\title{
Interpretative Pros Hen Pluralism: \\ from Computer-Mediated Colonization to a Pluralistic Intercultural Digital Ethics
}

\section{Charles Melvin Ess ${ }^{1}$}

Received: 22 January 2020 / Accepted: 19 June 2020 / Published online: 8 July 2020

(C) The Author(s) 2020

\begin{abstract}
Intercultural Digital Ethics (IDE) faces the central challenge of how to develop a global IDE that can endorse and defend some set of (quasi-) universal ethical norms, principles, frameworks, etc. alongside sustaining local, culturally variable identities, traditions, practices, norms, and so on. I explicate interpretive pros hen (focal or "towards one") ethical pluralism (EP(ph)) emerging in the late 1990s and into the twenty-first century in response to this general problem and its correlates, including conflicts generated by "computer-mediated colonization" that imposed homogenous values, communication styles, and so on upon "target" peoples and cultures via ICTs as embedding these values in their very design. I contrast different kinds of ethical pluralisms as structural apparatus for understanding what differences may mean and allow for, as these emerged in the 1990s forwards with EP(ph). As interwoven with phronēsis, a form of reflective judgment and virtue, EP(ph) more radically preserves irreducible differences and so fosters positive engagements across deep cultural differences. I show how EP(ph) emerged in the context of empirical research on "Cultural Attitudes towards Technology and Communication" (CATaC) beginning in 1998, and then in specific applications within Internet Research Ethics (IRE) beginning in 2000. I summarize its main characteristics and trace how it has further been taken up in ICE, IRE, Intercultural Information Ethics, and virtue ethics more broadly. I respond to important criticisms and objections, arguing that $\mathrm{EP}(\mathrm{ph})$ thus stands as an important component for a contemporary IDE that seeks an ethical cosmopolitanism in place of computer-mediated colonization.
\end{abstract}

Keywords Computer-mediated colonization · Phronēsis · ICT design · Overlapping consensus $\cdot$ Virtue ethics $\cdot$ Internet research ethics

Charles Melvin Ess

c.m.ess@media.uio.no

1 Department of Media and Communication, University of Oslo, Oslo, Norway 


\section{Introduction}

Broadly construed, ethical pluralisms (EPs) are conceptual frameworks for how we are to interpret or understand what difference means - in this article, primarily differences between diverse ethical frameworks as well as between diverse norms, beliefs, practices, and so on that define cultural identities. A basic version of EP assumes that such differences, in the absence of any connection in the form of common grounds or identities, allow or require us to simply let these differences stand (e.g., Cusveller 1998). More complex forms of EP articulate structures of difference and connectionfirst of all connection by way of shared agreements or common grounds (again, connection by way of identity): this structure of identities and difference is denoted here as EP(id). A particularly important example of this EP(id) is John Rawls' notion of "overlapping consensus," one that supports a modus vivendi pluralism exemplified in diverse ethnic groups living side by side, but without significant contact or engagement (1989). By contrast, more robust forms of EP are developed in Charles Taylor's notion of complimentarity and what I came to call interpretive pros hen ("towards one") ethical pluralism EP(ph), (Ess 2006). Both go beyond the grudging tolerance of modus vivendi $\mathrm{EP}(\mathrm{id})$ to articulate the possibilities of connection between persons and cultures that do not require shared identities that risk marginalizing defining differences. Specifically, EP(ph) articulates connection alongside difference in the form of shared reference or focal points, such as basic norms or principles, that are interpreted or applied differently in different cultural contexts. The irreducible differences between cultures are then more fully preserved via a connection formed by a shared pointing towards (pros hen- "towards one") a given principle or norm, in contrast with connection via identity. This conceptualization supports positive engagements across our cultural differences that do not require identity that risks suppressing our defining differences.

Moreover, EP(ph) relies centrally on phronēsis, a form of reflective judgment that is at once a virtue or capability that requires cultivation and practice-including its use in interpreting (judging) whether or not diverse cultural practices can be reasonably understood as diverse applications of a shared norm across otherwise irreducible differences. As such, phronēsis is trained in part by way of examples of what appear to be successful as well as unsuccessful judgments: for this as well as several additional reasons, I undertake here a chronological account of the development of $\mathrm{EP}(\mathrm{ph})$ that foregrounds specific examples illustrating such judgments and interpretations.

So the first section begins with a central challenge facing Information and Computing Ethics (ICE) and an Intercultural Digital Ethics (IDE) vis-à-vis the increasingly global use of these technologies, including the internet and internet-facilitated communication: most briefly, how to develop a global ICE that can endorse and defend some set of (quasi-) universal ethical norms, principles, frameworks, etc. alongside the equally vital endorsement and defense of local, culturally variable identities, traditions, practices, norms, and so on (Capurro 1990; Ess and Sudweeks 2001; Ess 2002b)? This question was not merely of theoretical interest to a few specialists. Rather, the 1990s' discourse of "clash of civilizations" (Huntington 1993) and "Jihad vs. McWorld" (Barber 1992, 1995) and their underlying dualisms established a real-world, especially political context that further sharpened urgency of addressing this question in its ethical and philosophical dimensions. These dualisms were further sharpened by my suspicion 
that these conflicts between the Western values, assumptions and beliefs driving such cultural homogenization, and the target cultures of these colonization processes, operated at more hidden and thereby more pernicious levels - namely, in the very design of the information and communication technologies (ICTs) themselves. These ethical concerns with the praxis and real-world implications of ICT design and their diffusion inspired the conference series "Cultural Attitudes towards Technology and Communication" (CATAC, 1998-2016) as prime test-bed for the development of pluralist conceptions. The first conference provided ample evidence of what I then called "computer-mediated colonization," a play on computer-mediated communication (CMC) (Ess 2002b). Philosophical approaches to resolving these dilemmas began here with Soraj Hongladarom's (1998) use of Michael Walzer's distinction between "thick" and "thin" moralities which served as a first model and example of a pluralist conception. What became $\mathrm{EP}(\mathrm{ph})$ subsequently unfolded both within succeeding CATAC conferences - as well as in the specific domain of an emerging internet research ethics (IRE), as sponsored by the Association of Internet Researchers (AoIR) at its first conference in 2000. Developing ethical guidelines that would work cross-culturally, respecting their distinctive cultural identities, traditions, ethical norms, and practices, while at the same time connecting these with some sort of shared (quasi-) universal norms, hence provided us with a second test-bed of examples and problems that could inform and refine the development of an emerging EP against real-world praxis. The first section concludes with specific examples from both CATAC and the AoIR ethics work that help illustrate both the problematics we sought to resolve by way of EP as these thus shaped the evolution of EP(ph) itself.

I then turn to $\mathrm{EP}(\mathrm{ph})$ as developed by 2006 and 2007, in conjunction with the possible kinds of relationships it seeks to make possible on both "ethical theoretical" and political and cultural levels (cf. Hiruta 2006, 227). Most ambitiously, EP(ph) seeks to go beyond John Rawls' modus vivendi EP(id) (1989) and even Charles Taylor's notion of complimentarity relationships (2002) to establish the possibilities of relationships across irreducible cultural differences. More broadly, EP(ph) is further taken up as an important component in an emerging Intercultural Information Ethics (IIE), ongoing IRE (franzke et al. 2020), and Shannon Vallor's specific development of the "techno-moral virtues" argued to be central to good lives of meaning and flourishing (2016, 54f.)

I then turn to a series of objections and replies primarily collected and summarized by the Confucian ethicist I then turn to a series of objections and replies primarily PakHang Wong (2019). These highlight important limitations of EP(ph): briefly, it is by no means the only element required in an ethical toolkit aimed at sustaining irreducible cultural differences alongside possible connections, and its use is at best a necessary, but not a sufficient condition for successful resolutions of these difficulties.

Given such caveats, EP(ph) stands a useful concept in the ongoing development of Intercultural Digital Ethics, specifically as EP(ph) addresses its thematic interests in countering the still prevailing dominance of "Western ethical perspectives, to the exclusion of broader ethical and socio-cultural perspectives"-precisely as "the ethical norms and values designed into these technologies collide with those of the communities in which they are delivered and deployed" (Aggarwal 2019, 1). I take this to mean, at least partly, precisely the interest in avoiding contemporary forms of computer-mediated colonization, now all the more powerfully weaponized by way of 
Big Data, algorithmic processes, surveillance capitalism, and the emerging Internet of Things. To do so, however, requires not only making use of $\mathrm{EP}(\mathrm{ph})$ as a distinctive framework of interpretation that allows us to interpret or judge whether and if so, how relationships and connections - not just shared common grounds, e.g., in a Rawlsian "overlapping consensus" - can stand alongside deep and irreducible differences defining diverse cultural traditions: as depending centrally on phronessis, the principle virtue synonymous with practical wisdom, EP(ph) entails a normative impulse toward the cultivation of the virtues and capacities needed to foster dialog and fruitful engagements across our deepest cultural divides. At best, EP(ph) reinforces Shannon Vallor's emphasis on civility (2016, 140-145) and, ideally, a twenty-first century cosmopolitanism countering what appears to be increasing conflicts and fragmentation still inspired by new forms of computer-mediated colonization.

\section{Philosophical and Political Backgrounds}

\subsection{Ethical Pluralism, Relativism, and Monism: an Initial Review}

Ethical pluralism (EP) is first of all a prominent component of meta-ethics - that is, our second-order ways of conceptualizing and analyzing about first-order ethical matters. EP centrally addresses problems catalyzed by deep, perhaps irreducible differences. In contemporary philosophical discussion, ethical pluralisms are first of all ways of conceptualizing and understanding different sorts of difference and connection. The distinctions between ethical pluralisms may seem subtle - specifically with regard to whether or not, and if so, precisely how, they conceptualize connection (starting with shared identities or common grounds): but we will see that these distinctions make for very significant real-world differences in applied ethics, if not in politics.

EP is primarily used to denote differences only between individual cultural and ethical traditions $(\mathrm{EP}(\mathrm{do}))$ : these differences are taken to be so fundamental that they exclude any form of connection alongside those differences - connection in the first instance of common grounds or elements that might be shared across or alongside those differences. For example, Bart Cusveller (1997) uses ethical pluralism to refer simply to "different codes of ethics" (266f.). Cusveller uses this insistence on irreducible differences only to defend including spiritual practices in nursing alongside more secular codes of ethics (1997, 271ff.).

This use of EP(do) risks, however, falling into an ethical relativism. Such relativism actively denies the existence or possibility "of ethical standards and norms that may be compelling and legitimate for more than the individual and/or specific ethnos" (Ess 2006, 216). That is, by insisting on irreducible differences between - in this case, different ethical codes - the ethical relativist seeks "to establish and justify tolerance towards a wide diversity of views, beliefs, practices, and cultures" (ibid). Such relativism, however, is deeply problematic in three ways. One, at the meta-ethical level, ethical relativism is logically contradictory. That is, it seeks to insist on a universal norm or practice of tolerance - but by arguing that there are no universal norms or practices (Ess 2020, 234f.). Secondly, we have seen that a central issue for ICE and IDE is how to establish a global ICE/IDE that is recognized as ethically legitimate and capable of being taken up in diverse cultural contexts, while simultaneously preserving 
the irreducible differences defining these diverse contexts. While ethical relativism precisely insists on respecting such irreducible differences - it does so at the cost of denying the possibility of any connections between diverse cultures, and so shortcircuits the project of a global ICE or Intercultural Information Ethics (IIE) at the outset.

Thirdly, in more political terms, ethical relativism thereby endorses an irreducible fragmentation between diverse cultures and peoples - a fragmentation that may further open up temptations to violence in the name of defending these differences. Specifically, a common response to these differences as portrayed in ethical relativism is a "modus vivendi" pluralism (Rawls 1989) that (grudgingly, perhaps) accepts such differences as final and irreducible, but only by letting "these differences stand," abdicating any hope of finding any form of connection, starting with common grounds, "between diverse views, approaches, norms, etc." (Ess 2006, 216; Ess 2020, 237-238). But in the case of real-world conflicts between diverse ethnic groups and between our larger collocations in nation-states, it is all too easy for these conflicts to erupt in violence. More broadly, as Luciano Floridi has pointed out, a first problem with modus vivendi pluralism is that it is simply not to be found (Ess 2006, 216).

At the same time, unfortunately, it is this "differences only" pluralism (EP(do)) that has prevailed, e.g., William Joseph Fitzpatrick (2004), B.C. Postow (2007), and Andrej J. Zwitter (2013). ${ }^{1}$ Somewhat more elaborate forms of EP have been more recently taken up, including Michelle Greenwood (2013), Allen Buchanan (2013), and Frits Gåvertsson (2017). All of these argue for a pluralism of diverse ethical frameworks, e.g., "Virtue ethics, ethics of care (also known as relational ethics), and [Habermasian] discourse ethics ..." (Greenwood 2013, 363). While there are some overlaps between these and $\mathrm{EP}(\mathrm{ph})$, none move to the level of articulating more robust forms of connection alongside irreducible differences in terms of either complimentarity (Taylor 2002) or pros hen ethical pluralism.

\section{2 "Jihad vs. McWorld," CATAC, and Internet Research Ethics}

The emergence of $\mathrm{EP}(\mathrm{ph})$ was initially catalyzed by a number of dualisms that emerged in 1980s and 1990s regarding computer-mediated communication (CMC). By 1989, James Carey characterized a "Manichean debate"-i.e., an either-or between the forces of light and goodness vs. those of evil and darkness - regarding CMC as a principle driver of globalization. The "digerati" - techno-optimists such as Nicholas Negroponte and Bill Gates - enthused that the diffusion of the internet would realize Marshall McLuhan's vision of "an electronic global village": this ostensibly revolutionary transformation would be no less radical and transformative than the invention of the printing press, if not fire (Ess 2001, 1-3).

\footnotetext{
${ }^{1}$ A possible early exception here is offered by Macklin (1997). Macklin aims towards a form of EP in a way that closely resembles what we will see below as interpretive pros hen ethical pluralism (EP(ph)) -i.e., one that understands apparently irreducible differences as rather diverse interpretations or applications of a shared norm or value. Macklin very helpfully portrays, for example, how informed consent may work differently in more individualist vis-à-vis more relational or collective cultures - an example that we will see developed precisely via EP(ph) by Soraj Hongladarom (2017). Macklin further shares with EP(ph) the aim of avoiding the dilemmas of ethical relativism vs. "ethical imperialism"- but she does not articulate an EP more explicitly than this $(1999,60)$. Rather, her formulation of EP sounds much more like Cusveller's (1998), i.e., an EP(do) that risks falling into ethical relativism.
} 
The political, economic, and military correlatives of these two poles were likewise cast in highly dualistic terms, beginning with Samuel P. Huntington's now infamous "Clash of Civilizations" (1993) and then, still more harshly, Benjamin Barber's framework of "Jihad vs. McWorld" $(1992,1995)$. The use of jihad in this way was and is deeply misleading and offensive to Muslims and anyone with an even passing familiarity with Islam: Barber's "journalistic" use of the term nonetheless set the terms, structure, and assumptions of much of the early debate and reflection concerning computer-mediated communication (CMC) as well as for those of us taking on the challenges of an emerging information and computing ethics (ICE) in conjunction with the emergence of ICTs generally and the internet specifically in the 1990s.

Broadly, Barber's "McWorld" describes a largely homogenous trade and consumer culture using English as its lingua franca, imposed in good measure by ICTs and the emerging internet. His "Jihad" denotes local autonomy movements that take up violence in the name of preserving cultural identity and survival (Ess 2001, ftn. 3, p. 30). "McWorld" thus expresses in terms of power a presumption of ethical monism and ethnocentrism (Ess 2020, 238-241, 51). Those willing to use force, whether social, economic, and/or military, to impose "McWorld" can more easily do so if they believe that there are homogenous ethical norms, principles, values, etc. (ethical monism). Whoever believes differently is by definition wrong and evil: hence imposing these norms monolithically upon "others," whether by persuasion or force, is justified. Similarly, the move toward conflict and violence in defense of local cultural identities, practices, norms, and beliefs may be fueled by the same ethical monism: we know what must be ethically right and universal - namely, our beliefs, practices, and so on, and so they must be defended against the invading imperialists. Lastly, if more subtly, ethical relativism can also support such violence: if there are no universally valid ethical norms and so on, then in the case of conflict, force rather than reason and debate may well be the only alternative (Ess 2006, 216; cf. Hiruta 2006, 230).

$\mathrm{EP}(\mathrm{ph})$ was originally sought after in hopes of discerning alternatives to these stark dilemmas - both in real-world terms as well as at the meta-ethical level. ${ }^{2}$ These efforts rested in part on the conviction, as Mary Midgley puts it, "Morally as well as physically, there is only one world, and we all have to live in it" ([1981] 1996, 119 in Ess 2009, 167). Nor is this solely a contemporary conviction: rather, EP(ph) is partially grounded in and shaped by ancient concerns for how to fruitfully resolve the conflicts between various forms of ethical and cultural monism vis-à-vis manifold cultural and ethical diversities into some form of cosmopolitanism as taken up in the 4th ct. B.C.E. Cynics and Stoics (Kleingeld and Brown 2019, 2f.; Ess 2004, 174). At the same time, however, we have seen how ICE, especially in connection with the internet and internet-facilitated communication, faces the challenges of ethical monism vs. ethical relativism and its real-world correlates in very specific ways.

\footnotetext{
${ }^{2}$ An anonymous reviewer has helpfully queried as to whether $\mathrm{EP}(\mathrm{ph})$ remains too ideal or abstract to be helpfully applicable in real-world conflicts. This first background for the development of EP(ph) rather shows how it is forged precisely vis-à-vis the very real conflicts and power struggles of globalization. While the broader direct impacts of EP(ph) are certainly limited - as we are about to see, EP(ph) emerges as both a theoretical and practical resolution within the $\mathrm{CaTaC}$ conference series and AoIR research ethics work-i.e., two specific test-beds for, e.g., ICT designers in development projects across the globe and researchers facing specific real-world choices rooted in a prime imperative to do no harm. These applications thus work on at least modest levels to counter ethnocentric homogenization and fragmentation.
} 


\subsection{Culture Shock, Blasphemy, and Computer-Mediated Colonization}

These problems were brought into still sharper and more complex focus by three closely related experiences and developments.

\subsubsection{Computer-Mediated Culture Shock}

The first was an experience of culture shock as I returned to Europe after 20 years for a conference in Oslo, Norway, on the topic of technology and democracy (Ess 2017). I quickly learned that my Norwegian colleagues' usages of $\mathrm{CMC}$, along with their reports of CMC usage in Scandinavia more broadly, were importantly different to the usages familiar to me from the US context. As but one example: young people in Norway were far more active in online environments than their US cohorts-a consequence, certainly, of the northern long dark winters, but also, I subsequently learned, of what is variously characterized as Norwegian introversion, shyness, and/or fear of conflict, i.e., distinctively culturally variable characteristics.

These discoveries crystallized a kind of philosophical blasphemy regarding thenprevailing technology in general and ICTs in particular. That is, contra the assumptions at the time that technologies are "just tools," i.e., somehow value-neutral in both their design and development (technological instrumentalism), it was clear instead that in the use of information and communication technologies (ICTs), "culture" makes a difference in their design, deployment, and uptake. ${ }^{3}$ This further led to a suspicion that the problems of McWorld-like imperialism and colonialism were still more complex at a more hidden and thereby more pernicious level—starting with the very design of these technologies as embedding specific cultural values and communicative preferences. Certainly, there were a very few voices beginning to this point in compelling ways in human-computer interaction (HCI) and what became known as participatory design (e.g., Suchman 1987). But within Information and Computing Ethics, much less against the noisy backdrop of US-centric techno-optimism, this was a somewhat radical turn. ${ }^{4}$

\subsubsection{Culture, Technology, Communication (CATAC): Confirmations of Computer-Mediated Colonization}

This experience led to a second element. My growing exploration of medium theory and media studies more generally made clear that in conjunction with philosophical theorizing, we needed data to analyze and address these issues-empirical findings,

\footnotetext{
${ }^{3}$ As we are about to explore more fully, "culture" is a notoriously ambiguous and contested concept, beginning with postcolonial critiques and affiliated warnings, e.g., against essentialism, i.e., ascribing some sort of static, homogeneous, universal, eternal character thereto (Ess 2002a). Indeed, by 2008 primary practitioners at $\mathrm{CaTaC}$ recommended dropping the concept altogether (e.g., Macfadyen 2008). Here I use it primarily as a shorthand term - as what Nocera and Camara (2010) denote as a "can-opener," useful for an initial opening up of these matters, but only for the sake of taking up far more nuanced analytical concepts and frameworks, especially in the matter of ICT design. See also Ess 2020, 49-53.

${ }^{4}$ The centrally important exception to this rule was the work of Rafael Capurro, who called attention to these issues as early as 1990. See Capurro (2007) for his overview of what he came to call Intercultural Information Ethics (IIE). A closer examination of the multiple intersections and joint influences between IIE and the evolution of EP(ph) explored here would be helpful and enriching, beginning with our shared work on an African Information Ethics-but exploring these in the detail they deserve is not possible here.
} 
specific examples, and experiences "from the field" of ICT design and implementation across a range of cultural sites (cf. Ess 2002a). And so, with the extraordinary help of Fay Sudweeks (now professor emerita, Murdoch University, Perth, Australia), we organized the first in what became a biennial conference series on "Cultural Attitudes towards Technology and Communication” (CATaC, 1998-2016). Fay's invaluable contributions began with her attention to the Aboriginal communities in Australia. CaTaC 1998 included a careful analysis of the cultural conflicts at work between Western ICT designers and their default commitments to openness, transparency, and equal access in communication vis-à-vis the knowledge systems of the Ngaluma, Injibandi, and Banjima peoples_-including such critical matters as who among a community holds what sorts of knowledge as secret and/or open to others, requirements not to speak the names of the dead, and so on (Turk and Trees 1998, 222).

At a still deeper level, Turk and Trees further highlighted the difficulties of defining "culture." As with many indigenous peoples, "culture" for these peoples is most centrally about the land and its places as "not just an arbitrary configuration of physical locations but an assemblage of places connected by meanings associated with traditional belief systems" (1998, 221)_contra, as commonly assumed in Western social sciences, cultural studies, philosophy, and so on, as a more codifiable and conceptually articulate worldview defined by ethical norms and obligations, definitions of community and community practices, basic assumptions regarding what counts as knowledge and reality, and so on (cf. Ess 2017).

This was but the first of multiple concrete examples exposing in exquisite detail specific, real-world contrasts and irreducible differences at multiple levels between the designers of ICTs and their "target" cultures. By 2002, an extensive, empirically informed account emerged that demonstrated first of all, contra the "techno-optimism" of 1990s' pundits regarding an "electronic global village" - the further away from North American cultural centers, the more striking the differences and conflicts between these sources and their "target" cultures. This begins within the USA itself, as different responses to ICT technologies in teaching and learning demonstrated strong differences regarding gender first of all, and then further among African-Americans, Hispanics, Asian-Americans, and Native Americans (Stewart et al. 2001). Similar differences between the German-, French-, Italian-, and Raetoromansch-speaking Swiss were documented by Lucienne Rey (2001). Still sharper divides and growing conflict and opposition to ICTs were further documented in the Middle East, including Israel (Dahan 1999) and Kuwait (Wheeler 2001), and in Asian societies such as Singapore and Japan (Heaton 2001), Malaysia (Abdat and Pervan 2000), and Indonesia (Rahmati 2000). As the opening example of Australian aboriginal peoples suggests, the sharpest differences could be documented among indigenous peoples in Malaysia (Harris et al. 2001), the Philippines (Sy 2001), and South Africa (Postma 2001). Most strikingly, the Solomon Islands' Kiribati people rejected internet access altogether for reasons closely similar to those first described by Turk and Trees (1998) - namely, fundamental conflicts between the epistemological and ontological assumptions of Western ICT designers and the Kiribati (Sofield 2000).

These initial reports from the field made It clear that "wiring the world" with ICTs and the internet was not an entirely benign exercise of spreading democracy, freedom of expression, prosperity, and so on; rather, the diffusion and/or imposition of these technologies was tantamount to "computer-mediated colonization" (Ess 2002b). Again, 
this presented a more pernicious form of colonization and imperialism because the imposition and diffusion of cultural values and communicative preferences was initially hidden within ICT as well as internet design and applications: it was hence less obvious and thereby more effective than more overt forms of imperialism and violence. This only increased the urgency of finding some sort of resolution - on practical as well as philosophical levels - between cultural homogenization, imperialism, and colonialism, on the one hand, vis-à-vis fragmenting and violent opposition in order to preserve local cultural identities.

Fortunately, early CATaC papers and panels also highlighted counter-examples that grounded and shaped subsequent research and further development of EP. To begin with, the Thai Theravadin Buddhist philosopher Soraj Hongladarom (1998) found that Thai Usenet group uses could be accurately understood in terms of Michael Walzer's distinction between "thick" and "thin" moral arguments: similarly, the internet could be understood as imposing a "thin" culture vis-à-vis "thick" local cultures that, as the Thai practices showed, were perfectly capable of resisting, for example, the imposition of English as a lingua franca (1988, 197-199). The thin culture of the internet, while shared globally, simultaneously allowed for robust, even flourishing "thick" local cultures. This became a primary model for EP(ph) as interpretive, namely one constituted by a "shared commitment to a fundamental norm, value, or guideline-[where] the interpretation or application of that norm differs in different contexts" (Ess 2002b, 182).

Moreover, contra the threats of homogenization via computer-mediated colonization, Deborah Wheeler (2001, 2003, 2006) and James Piecowye (2003) described young people in Muslim-majority countries such as Kuwait, Jordan, and the United Arab Emirates as "savvy users" who were perfectly capable of picking what elements of their own ("thick") cultures to maintain, and what elements of (comparatively "thin") Western culture they wished to appropriate. Wheeler noted, for example, that contra the cultural taboo against young women and men talking with one another without a chaperone, they did so extensively through the privacy and anonymity of chatroomssometimes leading to "love-marriages" in contrast with traditionally arranged ones (Wheeler 2003). Wheeler and Piecowye further showed how users in these countries rejected other Western cultural values and practices mediated through the Internet and the Web, such as pornography and consumerism more broadly.

These early examples thus forcefully demonstrated the very real risks of a computermediated colonization as an extension of the globalization processes threatening a culturally homogeneous McWorld — as additional examples also provided both empirical instances of non-violent resistance to such colonization, and, specifically, an early form of interpretive EP(ph). Further development took place within the highly applied ethical domain of internet research ethics.

\subsubsection{Ethical Pluralism and Applied Internet Research Ethics}

As internet research matured in the 1990s, it increasingly encountered often novel ethical challenges and dilemmas that were not immediately tractable with traditional research ethics. In particular, the increasingly global reach and use of the internet meant that internet research ethics (IRE) presented concrete examples of the broad problem of a global ICE/IDE - again, how to establish some set of (quasi-) universal ethical 
standards with a fundamental respect for and protection of local, culturally variable norms, beliefs, and so on? In our version of McWorld vs. Jihad, failure to resolve the dilemma would mean either the global imposition of US-based research ethics or the insistence on purely local traditions: the latter would fly specifically in the face of research aimed at pursuing the global reach and implications of these new technologies.

We began developing the initial guidelines for IRE in 2000 as part of the inaugural conference of the Association of Internet Researchers (AoIR). Our first committee of 20 colleagues included representation from Japan, Malaysia, and Thailand.

The first IRE guidelines were approved by AoIR in 2002 (Ess and the Association of Internet Researchers 2002 - simply denoted as IRE 1.0); these stand the foundation for two subsequent expansions and enhancements, denoted as IRE 2.0 (Markham and Buchanan 2012) and IRE 3.0 (franzke et al. 2020). Inspired by Hongladarom's initial example (Hongladarom 1998), we developed first versions of EP, beginning with one defined simply as allowing us "to recognize a range of specific ethical positions as legitimate, rather than either insisting on a single ethical value (monolithic ethical dogmatism) or simply giving up on ethics altogether and embracing ethical relativism" (Ess 2002b, 181). This was an interpretive EP for directly addressing cultural differences, defined as: "one in which there is shared commitment to a fundamental norm, value, or guideline - but the interpretation or application of that norm differs in different contexts" (Ess 2002b, 182).

A first practical example concerned when and under what conditions it would be permissible to record behaviors in a public space. Our Norwegian colleague, Dag Elgesem, informed us of the considerably tighter restrictions on such recordings in Norway as compared with the USA. But the justifications for each suggested an interpretive ethical pluralism: "in both cases, the expectations of the actors/agents involved are paramount," and so stand as a shared value: thereby the diverse requirements reflect two different interpretations or applications of this shared norm (ibid). A second example was offered by the legal scholar Joel Riedenberg (2000) and philosopher Diane Michelfelder (2001), as confronting the striking differences between US and European privacy laws. These differences could be understood via an interpretive EP conjoining privacy as a shared norm with two diverse frameworks of interpretation or application - starting with the more utilitarian approaches characteristic of the US vis-à-vis the more deontological approaches prevailing in the EU (Ess 2002, 182f.) For his part, Riedenberg argued for a convergence on what he called "the First Principles of Data Protection": "the differences we have noted result from differences in implementation, i.e., through 'either [current U.S.-style] liberal, market based governance or [current E.U.-style] socially-protective, rights-based governance"” (Riedenberg 2000, 1331f., in Ess 2002, 183). In turn, Michelfelder (2001) argued that "both U.S. and European law are rooted in a shared conception of fundamental human rightsconceptions articulated both in the 1950 European Convention for the Protection of Human Rights and in the U.S. Constitution itself' (Ess 2002b, 183).

Certainly, these examples are within diverse but still Western countries. ${ }^{5}$ Nonetheless, as we are about to see, they foreshadowed further applications across East-West divides. These examples thus provided concrete applications of an interpretive ethical pluralism that could resolve cross-cultural differences within a structure of shared

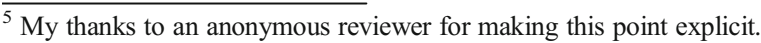


norms, values, principles, etc. as interpreted or applied differently through specific legal and cultural traditions, approaches, and so on. Within the specific and highly applied domains of IRE, these examples at the same time thus exemplify and meet the requirements of a global ICE/IDE - namely, to develop a global ethics that conjoins shared ethical commitments with the irreducible differences defining local cultural identities.

\section{Interpretive Pros Hen Ethical Pluralism}

Further developments - both within CATaC and subsequent AoIR work, in ICE more broadly (e.g., Ess 2004), as well as in the emerging field of Intercultural Information Ethics (Capurro 2007; Ess 2007b) - helped test and refine what I articulated as an interpretive pros hen ethical pluralism (EP(ph))(Ess 2006). I sketch out here the key features of $\mathrm{EP}(\mathrm{ph})$, in anticipation of the following discussion of important objections and replies.

\subsection{Interpretive Pros Hen Ethical Pluralism: Key Characteristics}

A prominent form of EP was already available in the form of Charles Taylor's notion of complementarity. The idea here is to move beyond an $\mathrm{EP}(\mathrm{do})$ that merely lets differences stand (e.g., Cusveller (1998) et al.) as well as beyond an EP(id) in which one or more homogenous elements are shared alongside differences defining cultural identities. The latter was available in the form of John Rawls' arguments for an overlapping consensus between diverse communities, and reflects our first instincts to find "common grounds" when confronted with deep cultural divides (1989). But these common grounds may be difficult to reach, and/or threaten leave us with a grudging modus vivendi pluralism which minimizes engagement across these differences. Madsen and Strong (2003) — in part, in reaction against the rising anti-Muslim sentiments following 9/11 — criticized this approach: "If we assume all reasonable people ought to share such common understandings, then we easily dehumanize those who in fact do not ("Can you believe how they treat women?" "They are animals and killers: they think abortion is all right." ...)" (2003, 12: in Ess 2006, ftn. 11, 217). Madsen and Strong rather endorsed Taylor's understanding of complimentarity as one that "would not merely tolerate ethical difference but would engage it as a path towards deeper forms of human community" (2003, 11, emphasis added, CME; Ess 2006, ftn 10, 217). Taylor put it this way: "The crucial idea is that people can bond not in spite of but because of difference. They can sense, that is, that their lives are narrower and less full alone than in association with each other" (2002, 191, in Madsen and Strong 2003, 11, in Ess 2006, ftn 10, 217).

I have argued that this sort of complimentarity is more fully articulated and defended by invoking Platonic and Aristotelian resources - specifically, Aristotle's account of pros hen ("towards one") equivocation. In terms of language, pros hen equivocals forge a middle ground between strict univocation (a term can have one meaning only) and strict equivocation (a term holds more than one meaning, each of which is utterly divorced from the other): e.g., "bat" in English can mean either a winged mammal or a wooden stick used for playing baseball. By contrast, we can call both an apple and 
one's appetite "healthy": the two meanings are importantly different, but not utterly divorced. An apple is healthy as it contributes to a state of health; an appetite is healthy as it reflects a body's good state of health. Both meanings are distinct and at the same time point toward - pros hen - a shared concept or term, namely "health." As Aristotle puts it: "... the term "healthy" always relates to health (either as preserving it or as producing it or as indicating it or as receptive of it ...." (Metaphysics 1003b2-4; cf. 1060b37-1061a7). In this way, the two distinct meanings of "healthy" are conjoined in a structure of both non-identical connection and irreducible difference. Their differences, to say it differently, stand alongside their connection through - indeed, their essential dependency on - a shared term or concept. This example may seem simple: but such pros hen equivocation and an underlying set of qualitative analogical structures of connection in the face of irreducible difference have been central in Western epistemology, metaphysics, and ethics. As a start, Aristotle's central example grounds his metaphysics: 'there are many senses in which a thing is said to 'be,' but all that 'is' is related to [pros hen] one central point, one definite kind of thing, and is not said to 'be' by a mere ambiguity" (Metaphysics 1003a33, Burrell $(1973,84)$ in Ess 2006, 218).

Analogy and analogical pros hen predication are further central in Plato and Aristotle as these allow for connection in the face of irreducible differences, e.g., Aristotle's "underlying nature" as otherwise epistemologically inaccessible (Physics 191a7-12; cf. Ess 1983, 41). This use becomes foundational for both Aquinas and Kant as they seek to elaborate on what is otherwise inaccessible to human knowing, specifically God and the noumena, respectively (Ess 1983).

Especially within the linguistic and then ethical realms, determining whether or not two diverse elements can be held together in such a qualitative analogical relationship is a matter of interpretation (as Plato's groundings make clear)—where such interpretation specifically requires the capacity of phronēsis, a form of reflective judgment, also translated as "practical wisdom," that is sharply distinct from more deterministic and deductive forms of judgment. Both Aristotle and Aquinas stress the role of phronēsis in making difficult ethical judgments sensitive to the unique particularities of specific contexts (Ess 2006, 218f.; cf. Kristjánsson 2014, 155f.). First of all, these judgments - echoing analogical predication-can be multiple and variable, both for a given person (e.g., at different stages of life) as well as between persons, as the phrase "judgment call" suggests: we recognize that more than one judgment call about a specific issue can be ethically legitimate. Phronetic judgments are thereby and of necessity open to further critique, debate, and revision: this multiplicity of often correct but still potentially mistaken judgments is made especially articulate, in fact, in Plato's use of the cybernetes - a steersman or pilot - as the exemplar (analogue) of ethical judgment as selfcorrecting (Republic I, 332e-c; VI, 489c). At the same time, phronesis is a virtue, i.e., a capacity or ability that must be practiced in order to be used well. ${ }^{6}$ This

\footnotetext{
${ }^{6}$ The cybernetes is manifestly the inspiration for Norbert Wiener's development of cybernetics as a "science of self-correcting systems" (1948). At the same time, Wiener's The Human Use of Human Beings (Wiener 1950-1954), as the first book-length development of what becomes ICE, explicitly invokes virtue ethics - and thereby becomes foundational for subsequent uses, including the most recent development of "ethicallyaligned design" of AI (IEEE 2019). For a more complete exposition of the relationships between phronēsis, virtue ethics, and ethics of care vis-à-vis Human-Machine Communication and ICT design, see Ess 2018, $243-246$.
} 
immediately means, however, that our interpretations as to whether or not there is a good analogy between two different practices, beliefs, values, etc. depends upon a capacity for phronetic judgment that must be practiced over time - and for which disagreement between persons will be common.

At the same time, however, if we consider that some of our practices, beliefs, values, etc. may be only analogically similar, rather than identical, such phronetic judgments via $\mathrm{EP}(\mathrm{ph})$ then allow for deep differences between cultures to stand rather than be overridden by a homogenous identity. A first example within ICE takes up irreducible differences between modern Western understandings of the self as an atomistic individual vis-à-vis Buddhist conceptions of the self as a pernicious "ego-illusion," one responsible for our suffering and so an illusion that must be overcome, e.g., through techniques of denying the self (musi or "no-self" in Japanese: Ess 2006, 222). These sharp differences directly entail opposite evaluations of individual privacy - namely, privacy as a positive good and basic right in democratic societies vs. "privacy" as something negative, shameful, or dirty. Nonetheless, using examples from Germany, Hong Kong, China, and Japan, I argue that these diverse cultural practices and attitudes toward privacy can be interpreted as taking "privacy" as the focal point toward which (pro hen) they aim and draw their related but irreducibly different meanings. Specifically, in China and Thailand, "privacy" is protected as a good primarily in the form of familial or group privacy vs. "privacy" as protected in Germany and the USA as primarily an individual good and right (Ess 2006, 223f.; for additional examples, see Ess 2007a, 2007b).

From here, EP(ph) found some use in the emerging Intercultural Information Ethics (Ess 2007a). In this direction, we have used EP(ph) to mark out possibilities of "ethical alignment" between both liberal-democratic societies and those that are not, i.e., thereby again going beyond a Rawlsian overlapping consensus (Hongladarom and Ess 2007, xv). EP(ph) has further continued to find application in the AoIR discussions of IRE (Markham and Buchanan 2012; Franzke et al. 2020) as well as in virtue ethics more broadly (Vallor 2016, 54-57). In particular, Soraj Hongladarom (2017) deploys EP(ph) in his analyses of Buddhist vs. Western conceptions of informed consent, i.e., as more relational vis-à-vis more individual, respectively. He further helpfully elaborates on the foundational emphasis in such a pluralism on preserving irreducible cultural differences: such a pluralism requires that specifically recognize and respect that a given national or cultural IRE is "... grown from the local source, meaning that the [ethical] vocabulary comes from the traditional and intellectual source of the culture in which a particular researcher is working" (Hongladarom 2017, 161; Franzke et al. 2020, 16).

Both in its origins - as grounded in the normative insistence on preserving the differences defining distinct culturally variable norms, practices, and so on-and in this specific articulation, EP(ph) insists on the integrity and legitimacy of local grounds and sources. This moves beyond more prevailing forms of EP that cross differences by way of shared common grounds (i.e., as a relation made possible only by way of a homogenous identity). More broadly, EP(ph) provides a conceptual framework that undergirds possible forms of cosmopolitanism that can counter otherwise prevailing tendencies to interpret ethical and cultural differences as a "clash of civilizations" (Huntington 1993) - or worse. 


\section{Objections and Replies}

$\mathrm{EP}(\mathrm{ph})$ is a sophisticated conceptual framework for interpreting how deep cultural differences that defy connection via identical elements as common grounds may nonetheless be phronetically judged to be ethically coherent with one another as they point toward a shared norm, value, belief, etc. $\mathrm{EP}(\mathrm{ph})$ begins and ends with the normative commitment to preserve and foster diverse cultural identities, so as to counter computer-mediated colonization broadly as it further serves to resolve problems of applied ethics within ICE, IIE, IRE, and virtue ethics more generally. Precisely as dependent upon phronetic judgments that will be multiple, partial, and intrinsically open to (cybernetic) self-correction, it thereby requires ongoing critique, dialog, and refinement by taking up such examples of both successful and erroneous judgments of whether or not, and if so how, $\mathrm{EP}(\mathrm{ph})$ can be useful vis-à-vis specific examples and cases. Finally, its development and application among the community of practitioners in $\mathrm{CaTaC}$ and IRE argue for its real-world usability.

But of course, it is open to important criticisms.

\section{1 $\mathrm{EP}_{(\mathrm{ph})}$ and Global Traditions}

We have seen that $\mathrm{EP}(\mathrm{ph})$ is catalyzed by central concerns to counter especially US-centric but also larger forms of Western cultural (and affiliated) imperialisms. The Socratic and Aristotelian roots of $\mathrm{EP}(\mathrm{ph})$, however, invite the criticism that it remains "Western" and thereby, contrary to its best intentions, only serves as yet one more, if unwitting example of such imperialisms. First of all, however, work in comparative philosophy and religion shows how resonance and harmony, as tied specifically to the proportions and analogies in Plato's interpretive pluralism and Aristotle's pro hen pluralism, are shared interests, along with similar forms of ethical pluralism, in Confucian thought, Daoism, and Buddhism, as well as in Islamic traditions (Ess 2006, 219f.). Whether we interpret these shared interests and EPs at a meta-level as either EP(id)s and/or EP(ph)s in turn — either way, the Western provenance of $\mathrm{EP}(\mathrm{ph})$ thereby does not seem to entail imperialistic imposition so much as meta-level resonance, harmony, and agreement.

I would also argue that Western origins alone do not provide sufficient conditions for a concept serving as prima facie imperialistic - especially given its primary normative grounding in emphases on seeking to respect and uphold cultural identity and diversity by way of conceptions of irreducible difference as joined through analogical pros hen relationships, in contrast with notions such as overlapping consensus as resting on some sort of identities that thereby risk devolving into ethnocentric hatred nonetheless (Madsen and Strong 2003, 12).

\subsection{Objections from Confucian Perspectives}

Confucian information ethicist Pak-Hang Wong has offered additional important objections to $\mathrm{EP}(\mathrm{ph})^{7}$

\footnotetext{
${ }^{7}$ Our joint presentation opening the IDES Symposium in Oxford (December 9, 2019) occasioned our exchanging criticisms and responses, including those taken up here. We are deeply grateful for the hospitality and sponsorship of the Digital Ethics Lab of the OII - specifically, Luciano Floridi, Mariarosaria Taddeo, and Nikita Aggarwal-for making these conversations and debates possible.
} 


\subsubsection{Objection: EP(ph) Can Be Misused to Justify Clear Moral Evils}

Replies This might well be true - especially as $\mathrm{EP}(\mathrm{ph})$ is dependent upon phronetic judgments that can well be mistaken. But where phronēsis is by definition capable of self-correction, it should be open to recognizing its error and seeking to overcome it. Moreover, I am certain that any ethical doctrine can be used contrary to its best intentions - but this misuse may not be an absolute reason for rejecting these doctrines. A prominent example would be Just War Theory, which includes the intention of minimizing noncombatant deaths and suffering. Within this context, the doctrine of double-effect insists that a primary aim of a military strike cannot be to target civilians intentionally: but if some civilian casualties are a secondary, unintended effect of a military strike as rather intended first of all against military targets (the first effect), then, at least up to some indeterminant point, the secondary effect is allowed for. The history of modern warfare is rife with examples of nations justifying military strikes with significant civilian casualties as "collateral damage": in this way, the doctrine becomes a useful tool, cynically exploited by those who appear to care very little for respecting and preserving civilian lives.

The possibility of misuse is thus always there-most especially when phronetic judgments are involved. The specific advantage of $\mathrm{EP}(\mathrm{ph})$ is, again, the insistence on the importance of recognizing when errors have been committed, and then seeking to avoid similar ones in the future. (This exercise in objections and replies is thus central in turn to the practice and development of phronēsis.)

\subsubsection{Objection: EP(ph) Gives Too Much Room for Diverse Interpretations of the Good-Leading Again to a Form of Relativist-Like "Tolerance" of Too Much Diversity, Including Instances or Examples that Are Hard to Defend as Good in a Strong Way}

Replies Again, this might well be true - but again, this is why phronēsis, reflective judgment is central to EP(ph), as the keystone virtue ("practical wisdom") that must be cultivated and practiced. Again, we will make mistakes, but we also learn from our errors of judgment.

\subsubsection{Objection EP(ph) Cannot Help Resolve Conflicts: Along with Paternalism, We Need Strong Commitments to Specific Values, Norms, Goods, "to Take} a Stand"-Using, e.g., the Distinction Between the Right and the Good to Avoid Clear Evils Such as Violence Against Women, Racism, Sexism, Genocide, etc.

Replies I certainly agree that EP(ph) by itself will not resolve all conflicts, nor always resolve conflicts properly - the first time around. But while wanting to emphasize the importance of phronēsis as a form of self-correcting judgment-I would further agree that at times we indeed must take a stand in ways that might shade into an ethical monism. For my part, inspired by Antigone and her many sisters and descendants in Western philosophical and religious traditions, I begin, like Kant, with human freedom as grounding basic ethical and political norms of respect, equality, and rights - not only 
rights to privacy, freedom of expression, but also rights to contest and disobey in the name of emancipations from regimes and structures that conflict with these (Ess 2019a). But this means that we need to be pluralistic about ethical pluralism-i.e., it is but one among several elements of our ethical toolkit. (And, it seems likely, attempting to judge when one ethical and/or meta-ethical theory is to take precedence of another, will still entail the use of phronēsis.)

\section{Concluding Remarks}

As these objections and replies reiterate, $\mathrm{EP}(\mathrm{ph})$ requires our careful use of phronessis - the principle virtue among the virtues (Vallor 2016, e.g., 24ff.). We have also seen that Vallor specifically identifies civility as one of her twelve techno-moral virtues, where civility would likewise contribute to the active engagements needed to move $\mathrm{EP}(\mathrm{ph})$ from a conceptual framework that holds open the possibilities of understanding our deepest differences as perhaps different interpretations or applications of shared values to the actual realization of dialog and engagement across those differences (Vallor 2016, 140-145). Both aspects are urgent-first as $\mathrm{EP}(\mathrm{ph})$, along with less robust forms of EP can help short-circuit the apparent dilemmas of McWorld vs. Jihad, of ethical monism vs. ethical relativism, and secondly as we can thereby cultivate civil dialog and humane relationships as cosmopolitans, not simply citizens of one particular ethnos or nation. ${ }^{8}$ In these directions, I am equally confident that Pak-Hang Wong's focus on Confucian emphasis on ritual will be helpful as well.

As these connections with virtue ethics and Confucian thought index in an initial way, the need for our cultivating such central capacities in ourselves and in our relationships with others is widely shared, whether or not it is couched in the terms of virtue ethics per se. So an early CATaC participant, Beverly Bickel (2003), observed in the context of her work with Muslim women in Afghanistan:

The democratic potential of the Net for promoting 'civic pluralism' will partly rely on its being constructed by those capable of negotiating global differences, creating multiple, complex meanings and crossing boundaries. (emphasis added, CME)

My hope is that by understanding these diverse forms of EP, most especially EP(ph) and its unique ways of helping us interpret and respond to irreducible cultural differences, IDE will thereby help us move forward in cultivating such capacities and thereby fostering greater engagement in the directions of dialog and peace-making - so as to counter, finally, the worst consequences of a computer-mediated colonization by fostering a cosmopolitanism instead.

\footnotetext{
${ }^{8}$ It is worth noting that EP(id)s can be discerned specifically in contemporary efforts to find ethical and legal approaches to the development of AI at both EU- and still more international levels (e.g., IEEE 2019, 53f.). For discussion and further examples, see Ess 2019b, 81-85.
} 
Funding Information Open Access funding provided by University of Oslo (incl Oslo University Hospital).

Open Access This article is licensed under a Creative Commons Attribution 4.0 International License, which permits use, sharing, adaptation, distribution and reproduction in any medium or format, as long as you give appropriate credit to the original author(s) and the source, provide a link to the Creative Commons licence, and indicate if changes were made. The images or other third party material in this article are included in the article's Creative Commons licence, unless indicated otherwise in a credit line to the material. If material is not included in the article's Creative Commons licence and your intended use is not permitted by statutory regulation or exceeds the permitted use, you will need to obtain permission directly from the copyright holder. To view a copy of this licence, visit http://creativecommons.org/licenses/by/4.0/.

\section{References}

Abdat, S., \& Pervan, G. P. (2000). Reducing the negative effects of power distance during asynchronous premeeting with using anonymity in Indonesian culture. In F. Sudweeks \& C. Ess (Eds.), Proceedings of the second international conference on cultural attitudes towards technology and communication (pp. 209215). Murdoch: Murdoch University Press.

Aggarwal, N. (2019). Call for papers for a special issue on Intercultural Digital Ethics.

Barber, B. (1992). Jihad vs. McWorld. The Atlantic Monthly, 53-63.

Barber, B. (1995). Jihad versus McWorld. New York: Times Books.

Bickel. B. (2003). Weapons of magic: Afghan women asserting voice via the net. Journal of ComputerMediated Communication 8(2). https://doi.org/10.1111/j.1083-6101.2003.tb00204.x.

Burrell, D. (1973). Analogy and philosophical language. New Haven: Yale University Press.

Buchanan, A. (2013). The challenge of ethical Pluralism (ch. 7). In The Heart of Human Rights. Oxford: OUP. Capurro, R. (1990). Towards an information ecology. In I. Wormell (Ed.), Information quality. definitions and dimensions (pp. 122-139). London: Taylor Graham.

Capurro, R. (2007). Intercultural information ethics. In R. Capurro, J. Frühbauer, \& T. Hausmanninger (Eds.), Localizing the internet. Ethical aspects in intercultural perspective (pp. 21-38). Munich: Fink.

Cusveller, B. (1998). Cut from the right wood: spiritual and ethical pluralism in professional nursing practice. Journal of Advanced Nursing, 28(2), 266-273.

Dahan, M. (1999). National security and democracy on the internet in Israel. Javnost-the Public, VI(4), 67-77.

Ess, C. (1983). Analogy in the critical works: Kant's transcendental philosophy as analectical thought. In Doctoral dissertation, Pennsylvania State University. Ann Arbor: University Microfilms International.

Ess, C. (2001). Culture, technology, communication: towards an intercultural Global Village. Albany: State University of New York Press.

Ess, C. (2002a). Cultures in collision: philosophical lessons from computer-mediated communication. Metaphilosophy, 33(1/2), 229-253.

Ess, C. (2002b). Introduction. Special issue on internet research ethics. Ethics and Information Technology, 4(3), 177-188.

Ess, C. (2004). Moral imperatives for life in an intercultural global village. In R. Cavalier (Ed.), The internet and our moral lives (pp. 161-193). Albany: State University of New York Press.

Ess, C. (2006). Ethical pluralism and global information ethics. Ethics and Information Technology, 8(4), 215-226.

Ess, C. (2007a). Can the local reshape the global? Ethical imperatives for humane intercultural communication online. In J. Frühbauer, R. Capurro, \& T. Hausmanninger (Eds.), Localizing the Internet. Ethical Aspects in an Intercultural Perspective (pp. 153-169). München: Wilhelm Fink.

Ess, C. (2007b). Cybernetic pluralism in an emerging global information and computing ethics. International Review of Information Ethics, 7, 1-31.

Ess, C. (2009). Digital media ethics. Oxford: Polity.

Ess, C. (2017). What's "culture" got to do with it? A (personal) review of CATaC (cultural attitudes towards technology and communication), 1998-2014. In G. Goggin \& M. McLelland (Eds.), Routledge companion to global internet histories (pp. 34-48). London: Routledge.

Ess, C. (2018). Ethics in HMC: Recent developments and case studies. In A. Guzman (Ed.), Human-machine communication: rethinking communication, technology, and ourselves (pp. 237-257). Berlin: Peter Lang. 
Ess, C. (2019a). Ethics and mediatization: Subjectivity, judgment (phronēsis) and meta-theoretical coherence? In T. Eberwein, M. Karmasin, F. Krotz, \& M. Rath (Eds.), Responsibility and resistance: Ethics in mediatized worlds (pp. 71-90). Berlin: Springer.

Ess, C. (2019b). Intercultural privacy: a Nordic perspective. In H. Behrendt, W. Loh, T. Matzner, \& C. Misselhorn (Eds.), Privatsphäre 4.0. Eine Neuverortung des Privaten im Zeitalter der Digitalisierung (pp. 73-88). Stuttgart: J.B. Metzler.

Ess, C. (2020). Digital media ethics (3rd ed.). Cambridge: Polity Press.

Ess, C., \& Sudweeks, F. (2001). On the edge: cultural barriers and catalysts to IT diffusion among remote and marginalized communities. New Media \& Society, 3(3), 259-269.

Ess, C. and the Association of Internet Researchers (2002). Ethical decision-making and Internet research: recommendations from the aoir ethics working committee. http://www.aoir.org/reports/ethics.pdf. Accessed 6 July 2020.

Fitzpatrick, W. J. (2004). Ethical pluralism without complementarity. Perspectives in Biology and Medicine, 47(2), 181-188.

Franzke, A.S., Bechmann, A., Zimmer, M., Ess, C. and the Association of Internet Researchers (2020). Internet research: ethical guidelines 3.0. https://aoir.org/reports/ethics3.pdf. Accessed 6 July 2020.

Gåvertsson, F. (2017). Ethical pluralism and moral conflict in Aeschylus's Oresteia. Philosophy and Literature, 41(1A), 24-39.

Greenwood, M. (2013). Ethical analyses of HRM: a review and research agenda. Journal of Business Ethics, $114,355-366$.

Harris, R., Bala, P., Songan, P., Lien, E. K. G., \& Trang, T. (2001). Challenges and opportunities in introducing information and communication technologies to the Kelabit Community of North Central Borneo. New Media \& Society, 3(3), 270-295.

Heaton, L. (2001). Preserving communication context: virtual workspace and interpersonal space in Japanese CSCW. In C. Ess (Ed.), Culture, technology, communication: towards an intercultural global village (pp. 213-240). Albany: State University of New York Press.

Hiruta, K. (2006). What pluralism, why pluralism, and how? A response to Charles Ess. Ethics and Information Technology 8 (4), 227-236.

Hongladarom, S. (1998). Global culture, local cultures, and the internet: the Thai example. In C. Ess \& F. Sudweeks (Eds.), Proceedings cultural attitudes towards communication and technology (pp. 187-202). Sydney: University of Sydney.

Hongladarom, S. (2017). Internet research ethics in a non-western context. In M. Zimmer \& K. KinderKurlanda (Eds.), Internet research ethics for the social age: new challenges, cases, and contexts (pp. 151163). Berlin: Peter Lang.

Hongladarom, S., \& Ess, C. (2007). Preface. In S. Hongladarom \& C. Ess (Eds.), Information technology ethics: cultural perspectives, xi- xxxiii. Hershey: Idea Group Reference.

Huntington, S. P. (1993). The clash of civilizations? Foreign Affairs, 72(3), 22-49.

IEEE. (2019). Ethically aligned design: a vision for prioritizing human well-being with autonomous and intelligent systems, 1st edition. https://ethicsinaction.ieee.org/. Accessed 6 July 2020.

Kleingeld, P. and Brown, E. (2019). Cosmopolitanism. The Stanford Encyclopedia of Philosophy Edward N. Zalta (ed.). https://plato.stanford.edu/archives/win2019/entries/cosmopolitanism/. Accessed 6 July 2020.

Kristjánsson, K. (2014). Phronesis and moral education: treading beyond the truisms. Theory and Research in Education, 12(2), 151-171.

Macfadyen, L. P. (2008). The perils of parsimony: "National culture" as red herring? In F. Sudweeks, H. Hrachovec, \& C. Ess (Eds.), Proceedings cultural attitudes towards communication and technology 2008 (pp. 569-580). Murdoch: School of Information Technology, Murdoch University.

Macklin, R. (1997). International research: ethical imperialism or ethical pluralism? Accountability in Research, 7, 59-83.

Madsen, R., \& Strong, T. B. (2003). The many and the one: religious and secular perspectives on ethical pluralism in the modern world. Princeton: Princeton University Press.

Markham, A., \& Buchanan, E. (2012). Ethical decision-making and internet research: recommendations from the AoIR Ethics Working Committee (Version 2.0). http://www.aoir.org/reports/ethics2.pdf. Accessed 6 July 2020.

Michelfelder, D. (2001). The moral value of informational privacy in cyberspace. Ethics and Information Technology, 3(2), 129-135.

Nocera, J. A., \& Camara, S. (2010). Reflecting on the usability of research on culture in designing interaction. In F. Sudweeks, H. Hrachovec, \& C. Ess (Eds.), Proceedings cultural attitudes towards communication and technology 2010 (pp. 150-162). Murdoch: Murdoch University. 
Piecowye, J. (2003). Habitus in transition? CMC use and impacts among young women in the United Arab Emirates. Journal of Computer-Mediated Communication 8(2). https://academic.oup.com/jcmc/article/8 /2/JCMC821/4584275. Accessed 6 July 2020.

Postma, L. (2001). A theoretical argumentation and evaluation of south African learners' orientation towards and perceptions of the empowering use of information. New Media \& Society, 3(3: September), 315-328.

Postow, B. C. (2007). Towards honest ethical pluralism. Philosophical Studies, 132, 191-210.

Rahmati, N. (2000). The impact of cultural values on computer mediated group work. In Sudweeks, F. and Ess, C. (eds.), Cultural attitudes towards technology and communication: Proceedings of the Second International Conference...Perth, Australia, 12-15 July 2000, 257-74. School of Information Technology, Murdoch University: Perth.

Rawls, J. (1989). The domain of the political and overlapping consensus. New York University Law Review, 64(2), 233-255.

Rey, L. (2001). Cultural attitudes toward technology and communication: a study in the "multi-cultural" environment of Switzerland. In C. Ess (Ed.), Culture, technology, communication: towards an intercultural Global Village (pp. 151-160). Albany: State University of New York Press.

Riedenberg, J. (2000). Privacy and electronic communications: hearing before the subcommittee on courts and intellectual property of the committee on the Judiciary House of Representatives; One Hundred Sixth Congress, second session, May 18, 2000. http://commdocs.house.gov/committees/judiciary/hju65439.000 /hju65439_0f.htm. Accessed 6 July 2020.

Sofield, T. (2000). Outside the net: Kiribati and the knowledge economy. In F. Sudweeks \& C. Ess (Eds.), Cultural attitudes towards technology and communication (pp. 3-26). Murdoch: School of Information Technology, Murdoch University.

Stewart, C. M., Shields, S. F., \& Sen, N. (2001). Diversity in on-line discussions: a study of cultural and gender differences in Listservs. In C. Ess (Ed.), Culture, technology, communication: towards an intercultural Global Village (pp. 161-186). Albany: State University of New York Press.

Suchman, L. (1987). Plans and situated actions: the problem of human-machine communication. New York: Cambridge University Press.

Sy, P. (2001). Barangays of IT: Filipinizing mediated communication and digital power. New Media \& Society, 3(3), 297-313.

Taylor, C. (2002). Varieties of religion today: William James revisited. Harvard University Press.

Turk, A., \& Trees, K. (1998). Culture and participation in development of CMC: Indigenous cultural information system case study. In C. Ess \& F. Sudweeks (Eds.), Proceedings Cultural Attitudes Towards Communication and technology (pp. 187-202). Sydney: University of Sydney.

Vallor, S. (2016). Technology and the virtues: A philosophical guide to a future worth wanting. Cambridge, MA: MIT Press.

Wheeler, D. (2001). New technologies, old culture: a look at women, gender, and the internet in Kuwait. In C. Ess (Ed.), Culture, technology, communication: Towards an intercultural global village (pp. 187-212). Albany: State University of New York Press.

Wheeler, D. (2003). The internet and youth subculture in Kuwait. Journal of Computer-Mediated Communication 8(2). https://doi.org/10.1111/j.1083-6101.2003.tb00207.x.

Wheeler, D. (2006). Gender sensitivity and the drive for IT: lessons from the NetCorps Jordan project. Ethics and Information Technology, 8, 131-142.

Wiener, N. (1948). Cybernetics: or control and communication in the animal and the machine. Cambridge: MIT Press.

Wiener, N. (1950-1954). The human use of human beings: cybernetics and society. Garden City: Doubleday Anchor.

Zwitter, A. J. (2013). From needs to rights - a socio-legal account of bridging moral and legal universalism via ethical pluralism. Politics and Governance, 1(1), 74-91.

Publisher's Note Springer Nature remains neutral with regard to jurisdictional claims in published maps and institutional affiliations. 